\title{
Role of Brain Magnetic Resonance Imaging in Assessment of Pediatric Developmental Delay
}

\author{
TOLBA S. ABD ELGHAFFAR, M.Sc.*; NAAILA A. ABU MADYAN, M.D.*; NADIA A. METWALY, M.D.* and \\ LAILA A. SELIM, M.D.** \\ The Department of Radio-Diagnosis, Faculty of Medicine, Al-AzharUniversity* and The Department of Paediatric Neurology, \\ Faculty of Medicine, Cairo University**
}

\begin{abstract}
Background: Developmental delay is defined as significant delay in one or more developmental domains.

Aim of Study: To evaluate prevalence of normal and abnormal MRI brain in children presenting with developmental delay.

Material and Methods: It is a prospective \& descriptive study of MRI Brain in 65 paediatric patients (34 males and 31 females), aged between three months to 18 years; presenting with developmental delay referred to Metabolic and Neurology Units at Abo El-Resh Hospital over a period of one year (May 2018 to May 2019). Clinical evaluation was performed by paediatric neurologist. MRI brain was done with appropriate sequences.
\end{abstract}

Results: The proportions of children having abnormal MRI findings in our study yield of $82 \%$. Most of them were in age group of three to 12 months (26\%). Males (51\%) were slightly more in number than females (49\%). Metabolic and degenerative disorders represent $41.5 \%$ of abnormal MR findings, congenital and developmental anomalies (26.2\%), non-specific findings $(7.7 \%)$, infection $(4.6 \%)$ and tumours (1.5\%). The most common category of metabolic disorders was lysosomal storage diseases. Congenital and developmental disorders were more common in males. The ventricles and white matter mainly the corpus callosum were the most commonly affected anatomical structures. The highest diagnostic yield was seen in patients presenting with developmental delay plus.

Conclusion: MRI can easily detect many specific aetiologic and pathophysiologic conditions, which will greatly help the clinician for proper diagnosis, treatment and counselling of the parents.

Key Words: Developmental delay-Leukodystrophy-MRI.

\section{Introduction}

DEVELOPMENT is a continuous process, which begins from conception and continues up until

Correspondence to: Dr. Tolba S. Abd Elghaffar, E-Mail: tolbasamir83@gmail.com maturity. However, during this process several factors like genetic, metabolic, endocrine, vascular, malformation syndromes, traumatic, infections, toxins \& environmental causes can have adverse effects of delay in milestone which can be evaluated using four domains of gross motor, fine motor and social and language skills [1].

Global Developmental Delay (GDD) is described as significant delay in two or more developmental domains (gross motor, fine motor, cognition, speech/language, and personal/social). Also, defined as performance at least two standard deviations below the mean of age appropriate [2]

Developmental delay is a common problem in pediatric age group and may become evident during infancy or early childhood. It becomes more apparent $\&$ therefore more often diagnosed in early school years [3].

According to the American Academy of Neurology and Child Neurology Society guidelines, neuroimaging is strongly recommended as part of the diagnostic evaluation for children with GDD [4].

Neuroimaging can reveal a cause in $55-85 \%$ of the cases. This wide variation could be attributed to patient selection criteria as the yield of useful diagnostic abnormalities is higher in a population selected for developmental delay with clinical features and using newer techniques [5].

Newer techniques such as DTI tractography can detect poorly developed white matter tracts such as the arcuate fasciculus and inferior longitudinal fasciculus in a subset of children with GDD. Also, MRS can help in diagnosis of developmental 
delay different aetiologies especially the metabolic disorders and brain infections [6]

Giving important information about different types of brain abnormalities, Magnetic Resonance Imaging (MRI) greatly helps to identify the diagnosis and the prognosis and helpful for parental counseling regarding the outcome of their child and to identify any possible risk of recurrence in the siblings [5].

Aim of the work was to evaluate prevalence of normal and abnormal MRI in children presenting with developmental delay.

\section{Patients and Methods}

\section{Patients:}

This is a prospective $\&$ descriptive study of MRI brain in 65 paediatric patients (34 males and 31 females), aged between three months to 18 years with age mean of 4.23 years; presenting with developmental delay referred to Radiology Department of El-Galaa Military Hospital and Six October University Hospital, referred from Metabolic and Neurology Units at Abo El-Resh Hospital over a period of one year (May 2018 to May 2019).

\section{Inclusion criteria:}

Children aged between 3 months- 18 years who presented with developmental delay/poor scholastic performance.

\section{Exclusion criteria:}

- Children aged $<3$ months and $>18$ years.

- Patient with relative or absolute contraindications to MR examination e.g. claustrophobia, patients with pace maker or metal implants.

- Patients suffering from ischaemic or traumatic brain injury.

\section{Methodology:}

-All cases were subjected to the following:

1- Full history (e.g. developmental, prenatal, delivery and postnatal) and family pedigree.

2- Clinical examination including generalized and neurological examination included weakness of limbs, hypo/hypertonia of limbs and abnormal posturing.

3- Investigations including basic laboratory investigations e.g. CBC, LFT, KFT, electrolytes, blood gasses, lactate and ammonia and extended metabolic screen e.g. urine organic acids profile as dictated by clinical picture of the patients. Results for whole exome sequencing if available were included.
4- Neurophysiological studies e.g. EEG, EMG and NCV.

5- Radiological studies e.g. brain MRI, MRS, brain CT, skeletal survey, abdominal ultrasound and ECG.

- Institutional ethical committee approval was obtained for this study.

\section{Patient preparation:}

Oral sedation utilizing Syrup Chloral Hydrate with a dosage of 5 to $10 \mathrm{mg} / \mathrm{kg}$ or short acting general anesthesia was given under supervision in children who were not getting sedated by oral drugs. In cases of general anesthesia, fasting for four hours and monitoring with ECG and pulse oximetry and continuous oxygen inhalational was performed during the entire scan.

\section{Imaging protocols:}

- MRI brain was performed using 1.5 Tesla (the Netherlands, Philips medical systems) at radiology department of El-Galaa Military Hospital for some cases and Six October University Hospital for the others.

- Patient position: Supine, and sedated if required. The head was placed in a specifically designed split, clear receiver coil and head immobilization was achieved.

- Scan time was around 12 minutes.

- The sequences used were T1WI, T2WI, DWI and FLAIR in axial plane. T2WI in coronal plane and sagittal T1WI. Contrast study, gradient/PD and MRS was undertaken wherever necessary.

- Average slice thickness was 3 and $5 \mathrm{~mm}$ and an interval of 3 to $5 \mathrm{~mm}$ was used.

- Gadolinium based contrast agent e.g. Magnevist or Omniscan was injected if required in a singledose $(0.1 \mathrm{mmol} / \mathrm{kg})$ in patients with normal renal functions.

\section{Data analysis:}

- The data obtained was then tabulated using Excel sheets. The patients details, clinical presentation, significant history, laboratory investigations, EGG, MRI findings and other radiological investigations were included in the excel sheets.

- The following structures were systematically evaluated at brain MR images:

1- Ventricles: For its size and morphology.

2- Corpus callosum: Thickness and morphology. 
3- Gray and white matter: The sulcation and gyration of the gray matter and abnormal white matter signals.

4- Basal ganglia: Morphology.

5- Brain stem: Morphology.

6- Cerebellum: Morphology and presence of cerebellar atrophy.

- Based on the MRI findings the children were categorized into two broad categories normal and abnormal. The abnormal MRI findings are further subdivided into the following groups:

1- Metabolic and degenerative disorders.

2- Congenital and developmental disorders.

3- Infection.

4- Neoplastic.

5- Nonspecific findings.

\section{Results}

In this study, 65 children with developmental delay were studied. Their age range was 3 months to 18 years with average age of 4.23 years and standard deviation $=3.74$. Out of 65 children, 53 $(81.5 \%)$ had abnormal brain MRI and $12(18.5 \%)$ had normal brain MRI, 34 (52.2\%) were male and $31(47.8 \%)$ were female.

Among 34 male patients with developmental delay, 27 had abnormal brain MRI and among 31 female patients, 26 had abnormal brain MRI. There is no relation between abnormal brain MRI and gender as $p$-value $=0.64(>0.05)$. Patients were divided into five age groups: 3 months to 1 years, 1 to 2 years, 2 to 5 years, 5 to 8 years and 8 to 18 years as it clear in (Table 1).

Table (1): Age and sex distribution of study population with normal and abnormal MRI.

\begin{tabular}{lcccc}
\hline \multirow{2}{*}{ Parameter } & \multicolumn{2}{c}{ Abnormal (N=53) } & \multicolumn{2}{c}{ Normal (N=12) } \\
\cline { 2 - 5 } & Number & $\%$ & Number & $\%$ \\
\hline Age: & 14 & 26.42 & 3 & 25 \\
$\quad$ months-1y & 10 & 18.87 & 1 & 8.33 \\
1-2y & 12 & 22.64 & 4 & 33.33 \\
2-5y & 6 & 11.32 & 3 & 25 \\
5-8y & 11 & 20.75 & 1 & 8.33 \\
8-18y & & & & \\
Sex: & 27 & 50.94 & 7 & 58.33 \\
$\quad$ Males $(\mathrm{n}=34)$ & 26 & 49.06 & 5 & 41.67 \\
Females $(\mathrm{n}=31)$ & & & & \\
\hline
\end{tabular}

Based on history and clinical details, it was seen that only 3 child (5.7\%) with abnormal MRI finding presented only with developmental delay and 50 child $(94,3 \%)$ presented with developmental delay and additional features, such as seizures, neurological deficits, abnormalities of head size, facial dysmorphism, cleft lip/palate, visual and auditory disturbances, gait disturbances, motor disturbances, consanguinity, low birth weight, chest or PNS infection. The yield was very high in children with developmental delay plus as compared to children with only developmental delay as depicted in (Table 2).

Table (2): Classification according to the clinical presentation of study population with normal and abnormal MRI.

\begin{tabular}{lllllll}
\hline \multirow{2}{*}{ Parameter } & \multicolumn{2}{c}{$\begin{array}{c}\text { Abnormal } \\
(\mathrm{N}=53)\end{array}$} & & \multicolumn{2}{c}{$\begin{array}{c}\text { Normal } \\
(\mathrm{N}=12)\end{array}$} \\
\cline { 2 - 3 } & Number & $\%$ & & Number & $\%$ \\
\hline Clinical presentation: & & & & & \\
Only developmental delay & 3 & 5.66 & & 4 & 33.33 \\
Developmental delay plus & 50 & 94.34 & 8 & 66.67 \\
\hline
\end{tabular}

The MRI findings were compiled, evaluated and divided into six categories based on the etiology as follows:

1- Normal: 12 patient (18.5\%).

2- Metabolic and degenerative disorders: 27 patient $(41.5 \%)$.

3- Congenital and developmental disorders: 17 patient $(26.2 \%)$.

4- Infection: 3 patient (4.6\%).

5- Neoplastic diseases: Only one patient (1.5\%).

6- Nonspecific findings-includes enlarged subarachnoid spaces and arachnoid cysts, etc.: 5 patient (7.7\%), these MRI finding represented in Fig. (1) \& (Table 3 ).
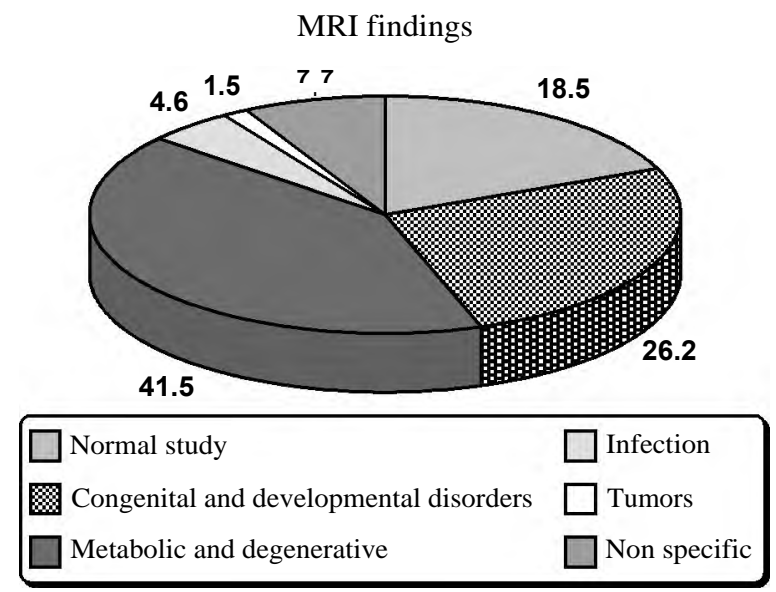

Fig. (1): Etiological classification based on MRI findings.

Normal MRI brain findings were seen in 12 $(18.5 \%)$ of pediatric patients presenting with developmental delay. These children were advised 
further evaluation to diagnose the etiology of developmental delay. Abnormal morphological appearance was seen in the remaining 53 patients. The most common abnormality encountered in present study was metabolic and degenerative diseases seen in 27 cases like Leigh disease, Gluteric aciduria, Glycoprotein lysosomal storage disorder, Tay-Sachs disease, Krabbe disease, Guilllian Barre syndrome, Wilson disease, Hallervorden Spatz Disease, MPS, Galactosemia, Vanishing white matter disease, Axonal neuropathy and Anterior horn cell disease.

Table (3): Etiological classification based on MRI findings.

\begin{tabular}{lcc}
\hline MRI findings & $\begin{array}{c}\text { Number } \\
\text { of cases }\end{array}$ & $\%$ \\
\hline Normal study & 12 & 18.5 \\
Congenital and developmental disorders & 17 & 26.2 \\
Metabolic and degenerative & 27 & 41.5 \\
Infection & 3 & 4.6 \\
Tumors & 1 & 1.5 \\
Non specific & 5 & 7.7 \\
\hline Total & 65 & 100 \\
\hline
\end{tabular}

Cortical malformation found in 17 cases like Blake's pouch cyst, dandy walker malformation, Agenesis of corpus callosum, Joubert's syndrome, Chiari malformation, Cerebral atrophy, AVM, Neurofibromatosis type I and CSF disorder like hydrocephalus and aqueduct stenosis.

Congenital infection like CMV and herpes encephalitis was presented in 3 cases and a case of recurrent astrocytoma was seen. Nonspecific abnormalities were found in 5 cases like prominent CSF spaces, vascular malformation and arachnoid cyst.

In this study, the most common abnormality encountered in the females was metabolic and degenerative diseases seen in 17 cases with $p$-value about 0.04. While, Congenital and developmental disorders were more common in males with $p$ value about 0.02 as shown in (Table 4).

Table (4): Gender-wise comparison of the patient's categories.

\begin{tabular}{lccc}
\hline Radiological diagnosis & $\begin{array}{c}\text { Female } \\
(\mathrm{n}=31)\end{array}$ & $\begin{array}{c}\text { Male } \\
(\mathrm{n}=34)\end{array}$ & $\begin{array}{c}p- \\
\text { value }\end{array}$ \\
\hline - Normal study & 5 & 7 & 0.643 \\
- Metabolic and degenerative & 17 & 10 & 0.0377 \\
$\begin{array}{l}\text { disorders } \\
\text { - } \begin{array}{l}\text { disongenital and developmental } \\
\text { - Infection }\end{array}\end{array}$ & 4 & 13 & 0.0203 \\
- Neoplastic diseases & 1 & 2 & 0.6102 \\
- Nonspecific findings & 1 & 2 & 0.2912 \\
\hline & 3 & 2 & 0.5663 \\
\hline
\end{tabular}

It worth mention that majority of abnormal MRI finding belonged to 3 months to 1 year age group while, majority of normal MRI finding belonged to 2 to 5 years age group as depicted in Fig. (2).

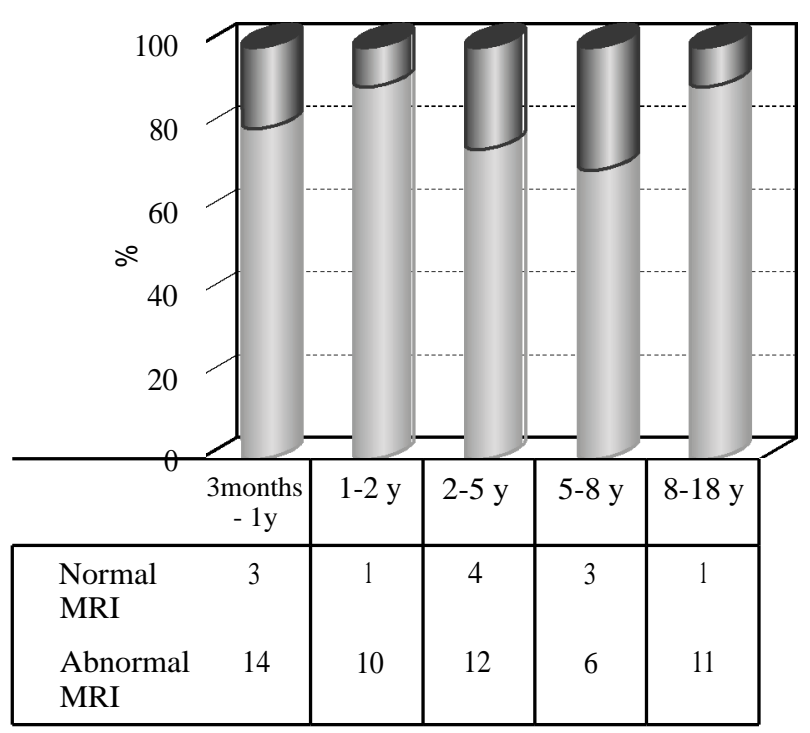

Fig. (2): Age distribution of study population with normal and abnormal MRI.

The distribution of affected anatomical structures in patients with abnormal MRI (53 cases) was analyzed and is presented in (Table 5). Abnormalities of ventricles, white matter and corpus callosum were found to be most common; as seen in $57 \%, 51 \%$ and $26 \%$ cases respectively. The proportion of children with abnormal findings in basal ganglia, cortical gray matter, cerebellum and brainstem were $19 \%, 11 \%, 21 \%$ and $9 \%$ respectively. Nonspecific abnormalities were found in 9\% of children; like prominent extra-axial spaces, AVM and arachnoid cyst.

Table (5): MRI findings in relation to anatomical structures $(\mathrm{N}=53)$.

\begin{tabular}{lll}
\hline Anatomical structures & No. & $\%$ \\
\hline Ventricles & 30 & 56.60 \\
White matter (abnormal MR signal) & 27 & 50.94 \\
Corpus Callosum & 14 & 26.42 \\
Cortical Gray Matter & 6 & 11.32 \\
Basal Ganglia & 10 & 18.87 \\
Brainstem & 5 & 9.43 \\
Cerebellum & 11 & 20.75 \\
Non specific & 5 & 9.43 \\
\hline
\end{tabular}

\section{Discussion}

The prevalence of developmental delay is 5$10 \%$ of children. The causes of developmental can be classified as genetic (Down's syndrome), metabolic, endocrine (congenital hypothyroidism), traumatic, environmental causes perinatal or con- 
genital neuroinfections (cytomegalovirus, toxoplasmosis), toxins (fetal alcohol syndrome) and perinatal asphyxia [7].

MR imaging is an important part of the comprehensive evaluation of children with developmental delay, as many specific aetiologic and pathophysiologic conditions that lead to developmental delay can be detected easily [8]

Detecting etiology of developmental delay greatly helps the clinician in counseling the concerned families and provides for a more accurate prognosis. Thus helping families to accept the problem better and stop their efforts for diagnosis and pay more attention to training [9]

The yield of a neuroimaging study increases when it is done in presence of specific problems such as microcephaly, seizure disorder or focal neurologic deficit [10].

So, brain imaging is recommended as a firstline investigation for patients with microcephaly, macrocephaly, seizures or abnormal neurological findings. For others, imaging may be postponed until first-line genetic and metabolic investigations have been performed [11]

In the current study, evaluation of developmental delay was done in 65 pediatric patients with clinical diagnosis of developmental delay referred to Metabolic and Neurology Units at Abo El-Resh Hospital over a period of one year. MRI findings in addition to clinical presentation, significant history, laboratory investigations, EGG, and other radiological investigations if available were collected and analyzed.

The pediatric patient age group was three months to 18 years with mean age was about 4.23 years and standard deviation of 3.74. Male were $34(52.2 \%)$ and $31(47.8 \%)$ were female.

The proportions of children having abnormal MRI findings in our study of 65 cases yield of $82 \%$ (53 cases). Similar yield of MRI has been reported by Ali et al., [5], Pranay \& Chitnis, [7], Jabeen et al., [9], Dasan \& Deepashree, [10], Konde et al., [12] and Ramya et al., [13] who had a yield of $79 \%, 72 \%, 64 \%, 68 \%, 62 \%$ and $66 \%$ respectively. Wide range of such yield could be due to the patient selection criteria as the yield is higher in a population selected for developmental delay with additional clinical features e.g. epilepsy and by using newer techniques e.g. MRS and DTI tractography.
Most of the children with abnormal MRI findings in our study were in age group of three to 12 months $(26 \%)$ with the next peak at two to five years $(23 \%)$, as most of older children was diagnosed younger and some of them follow-up in metabolic unit. Males (51\%) were slightly more in number than females (49\%). There is no relation between abnormal brain MRI and gender as $p$ value $=0.64(>0.05)$. Similar age of presentation and sex incidence was noted in the studies performed by Ali et al., [5], Pranay \& Chitnis, [7], Dasan \& Deepashree, [10] and Konde et al., [12] This is probably because children with developmental delay are identified more frequently when they are younger and probably evaluated earlier. Also some findings such as delayed myelination are recognized in younger children and normalize later in life.

Based on the MRI findings, we have classified MR features into various aetiologies as described in (Table 3), which include metabolic and degenerative disorders, congenital and developmental disorders, infection, neoplastic disease and nonspecific findings e.g. enlarged subarachnoid spaces and arachnoid cysts.

Konde et al., [12] and Ramya et al., [13] have classified their MRI findings into aetiological categories; in which congenital and developmental anomalies ranked higher than metabolic and neurodegenerative disorders which is against what we have encountered in our study as it was done to pediatric patients referred to metabolic and neurology units. We found that degenerative/metabolic diseases causing developmental delay was the most common finding in our study which was similar to Jabeen et al., [9] as he reported leukodystrophy as more common finding (30\%) than congenital malformations (15\%).

Congenital and developmental disorders were more common in males with $p$-value about 0.02 . Jabeen et al., [9] noted that leukodystrophy occurs with equal frequency in both male and female children while, males were affected more than females in congenital malformations as $3 \%$ were female and $20 \%$ were male.

The present study had 27 cases $(41.5 \%)$ included in degenerative/metabolic subgroup; like leigh disease Fig. (3), Gluteric aciduria, Glycoprotein lysosomal storage disorder, Tay-Sachs disease, Krabbe disease, Guilllian Barre syndrome Fig. (4), Wilson disease, Hallervorden Spatz disease, MPS, Galactosemia, Vanishing white matter disease, Axonal neuropathy and Anterior horn cell disease. 

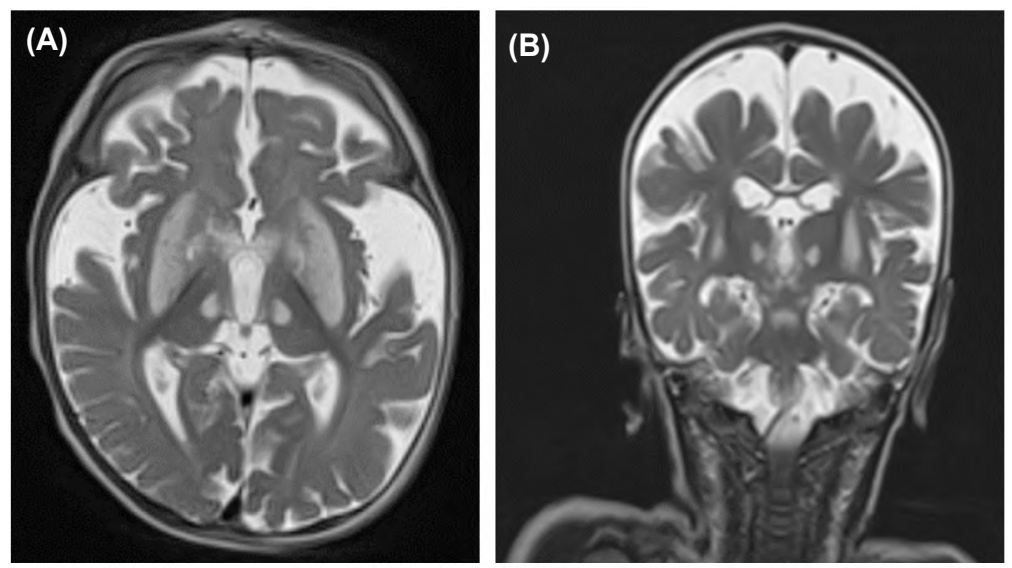

Fig. (3): Leigh disease in seven months old male. (A) Axial T2 (B) Coronal T2 MR images showing accentuated extra-axial CSF spaces, bilateral symmetrical whole basal ganglia, thalamic central foci and brain stem areas of high $\mathrm{T} 2$ signal intensity. (C) MRS Image revealed large Lactate peak denoting anaerobic glycolysis, elevated $\mathrm{Cho} / \mathrm{Cr}$ ratio denoting membrane turnover and no significant reduction of NAA.
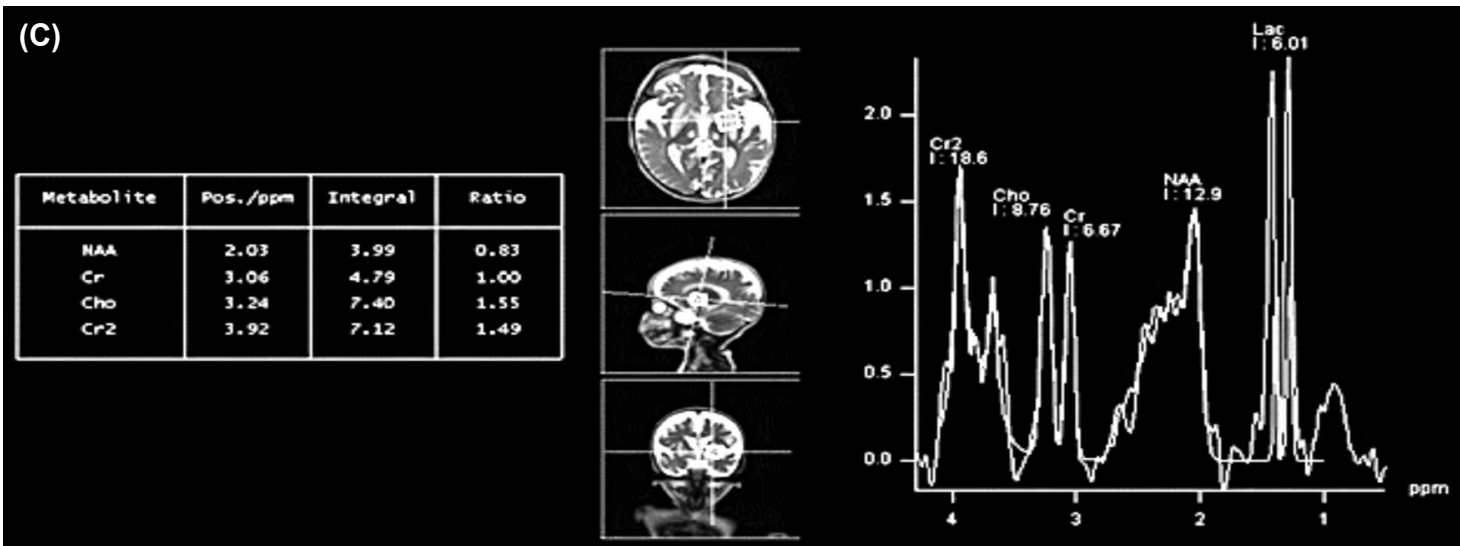

The most common metabolic category was lysosomal storage diseases (5 cases) and diseases caused by mitochondrial dysfunction followed by disorders of amino acid metabolism (4 cases). The most common lysosomal storage disease was $\mathrm{Mu}-$ copolysaccharidosis ( 2 cases), this was in line with Elmonem et al., [15] study. Gluteric aciduria type I Fig. (5) was most common disorder of amino acid metabolism. Arif et al., [14] reported that the most common metabolic category in their study was amino acid metabolism disorders.

The congenital and developmental anomalies have distinctive clinical and radiological findings, and their identification is very important in order to prevent recurrence and helps in parent counseling. We have found 17 such cases $(26 \%)$; which fit into this category such as Agenesis of corpus callosum Fig. (6) and Joubert syndrome Fig. (7); whereas Konde et al., [12] and Ramya et al., [13] reported lower incidence about $12.5 \%$ and $12 \%$ respectively as they included neurovascular diseases and trauma in their studies which was excluded in ours.

Konde et al., [12] reported few cases with features of infection (5\%) likely meningitis, encepha- litis and cerebral abscess. And 2 cases of posterior cranial fossa lesion likely Medulloblastoma were also reported (1.6\%). The present study had 3 cases (4.6\%) had CMV or HSV infection Fig. (8) and one case of recurrent astrocytoma.

Based on history and clinical details, it was seen that only $11 \%$ patients presented with only developmental delay rest $89 \%$ presented with developmental delay and additional features such as epilepsy, neurological deficits, abnormalities of head size, facial dysmorphism, cleft lip/palate, visual and auditory disturbances, gait disturbances, motor disturbances, social and cognitive problems, consanguinity or bad obstetric history. This result is similar to study performed by Ali et al., [5]

The 53 cases with abnormal MRI were evaluated for involvement of various anatomical structures. Abnormalities of ventricles, white matter and the corpus callosum were most common; seen in $57 \%, 51 \%$ and $26 \%$ of cases respectively. Also, Ali et al., [5] found that ventricles (62\%) and white matter mainly the corpus callosum $(58 \%)$ were the most commonly involved structures, while the other structures involved were almost similar to present study. We found that abnormal findings in cerebellum $(21 \%)$ more common than basal ganglia 
(19\%). Cortical gray matter and brainstem abnormalities were the least common.

The main drawback of the present study was the smaller sample size and the shorter time. In addition, some cases could be classified as metabolic, neurodegenerative or congenital, yet had not sufficient investigation to reach final diagnosis, for example proper genetic confirmation is greatly lacking due to financial restrictions of the Egyptian health care system. Children with developmental delay not undergoing brain MRI examination as a part of their investigation were not included in the study.
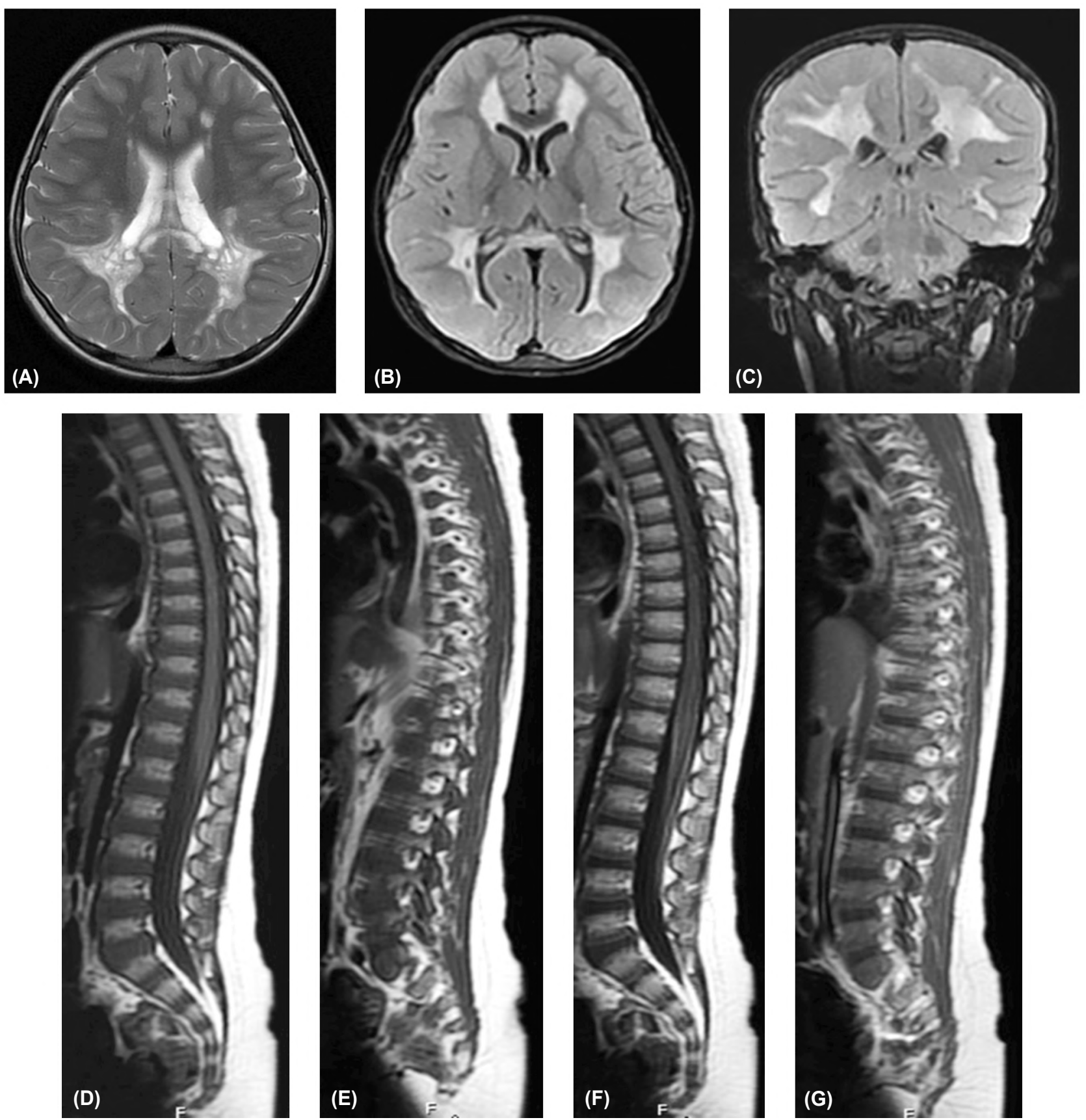

Fig. (4): Guilllian Barre syndrome associated with metachromatic leukodystrophy in four years old female. (A) axial T2, (B) Axial FLAIR and (C) Coronal FLAIR brain MR images revealed altered signal intensity of the cerebral white matter being hyper-intense at T2/FLAIR MR series. (D) and (E) Are sagittal dorsolumbar MR images without contrast, $(\mathrm{F}, \mathrm{G})$ Are sagittal $\mathrm{T} 1$ dorsolumbar MR images with contrast, they showed relatively thickened and enhanced nerve roots along the whole dorsal nerve roots and the cauda equine nerve roots, the spinal cord is mildly swollen with no significant intra medullary abnormal signal. 

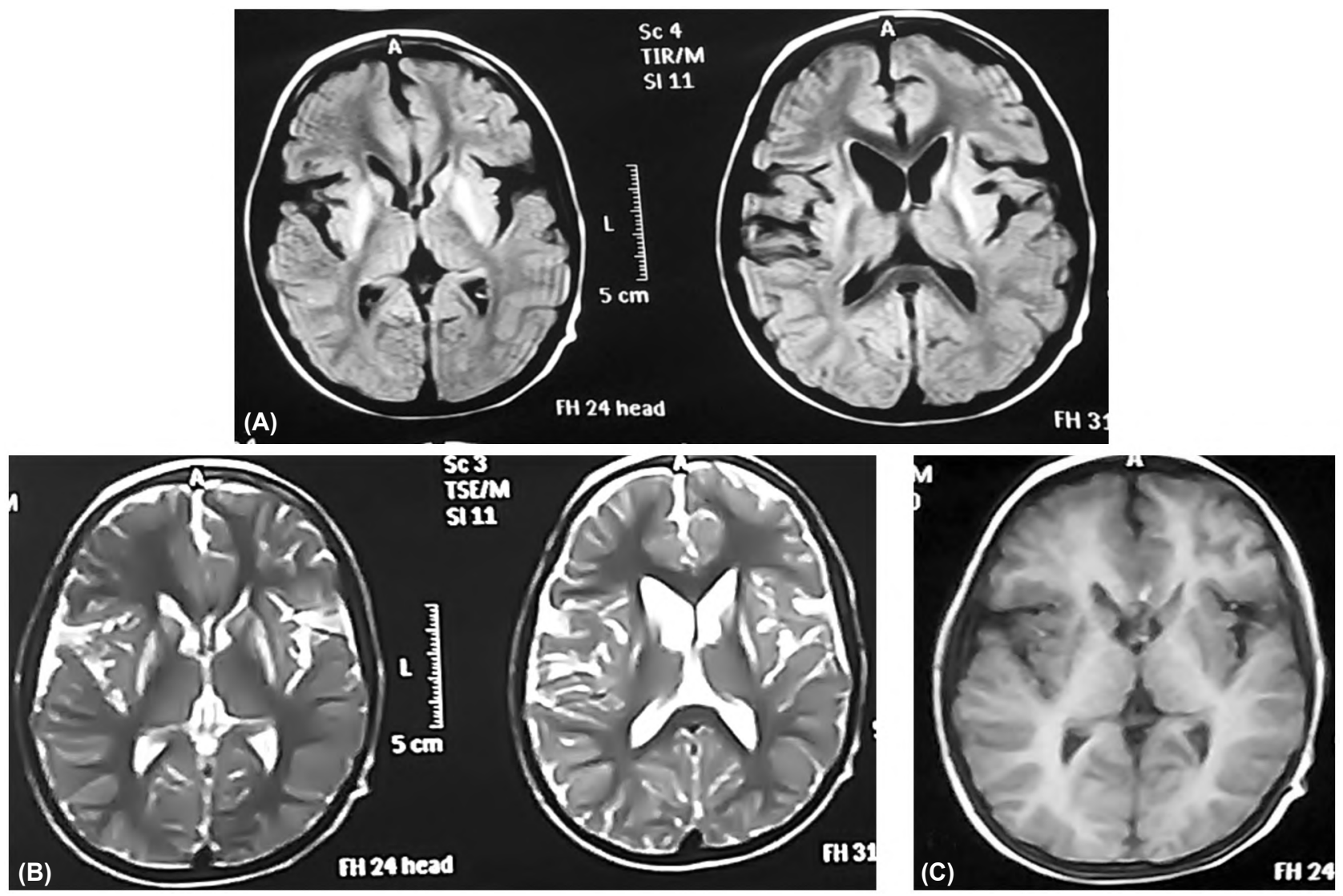

Fig. (5): Gluteric aciduria type I in five years old male. (A) Axial FLAIR MR image, (B) Axial T2 MR image, (C) Axial T1 MR image. They show prominent extra-axial CSF spaces including cortical sulci, Sylvain fissures and basal cisterns. Bilateral symmetrical caudate and lentiform nucleus high signal in T2 and FLAIR and low in T1.

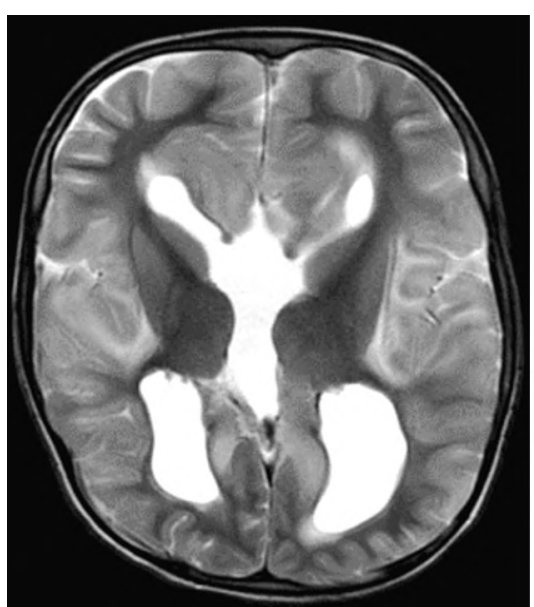

Fig. (6): Agenesis of corpus callosum in five years old male. Axial T2 MR Image show agenesis of corpus callosum with widely separated bodies of both lateral ventricles, thickened cortices with preserved cortico medullary differentiation.
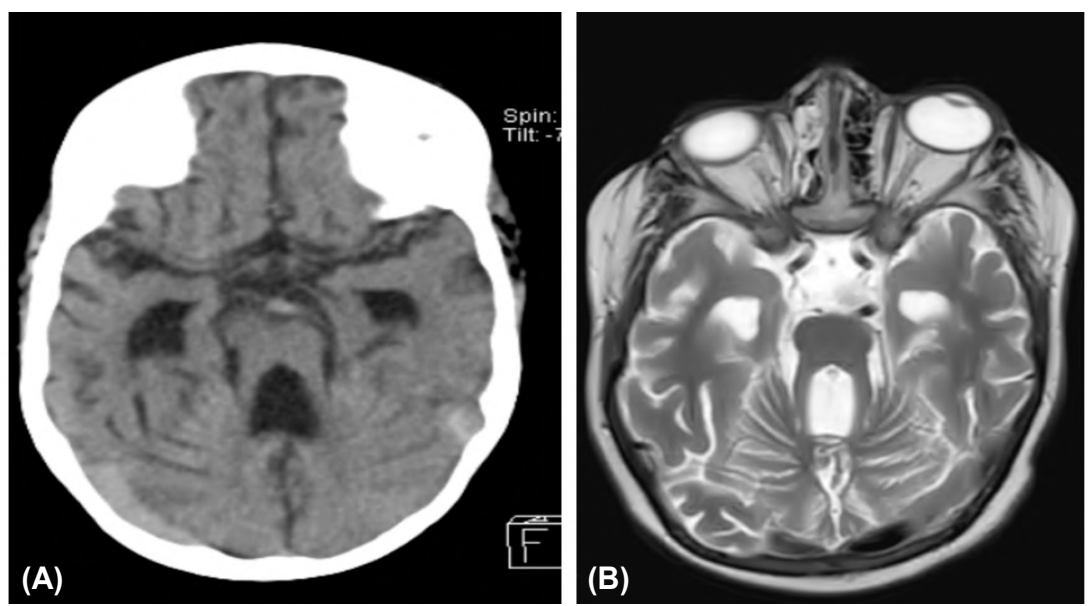

Fig. (7): Joubert syndrome in a nine years old male. (A) Axial CT and (B) Axial T2 MR image showed elongated relatively thickened superior cerebellar peduncle giving the molar tooth appearance (Joubert syndrome). 

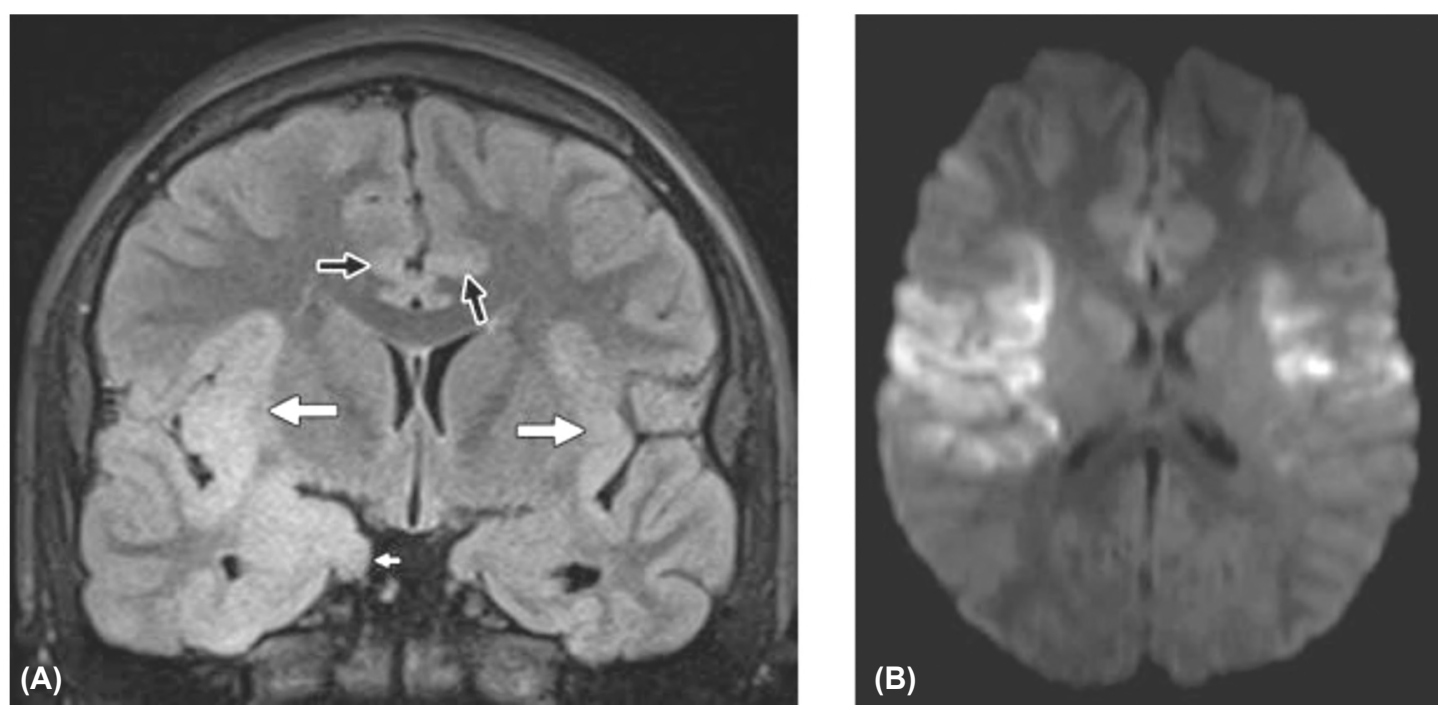

Fig. (8): Herpes simplex virus 1 encephalitis in 12-year-old boy with diagnosed by CSF polymerase chain reaction. (A) Coronal T2-weighted FLAIR image shows swelling and high signal intensity involving both insulae (long white arrows), right mesial temporal lobe and cingulate gyri (black arrows). Note mild right uncal herniation (short white arrow). (B) Axial DW image shows high signal intensity in affected cortex.

\section{References}

1- MOMEN A.A., JELODAR G. and DEHDASHTI H.: Brain Magnetic Resonance Imaging Findings in Developmentally Delayed Children. International Journal of Paediatrics, Article ID 386984, 2011.

2- BATTAGLIA A. and CAREY J.C.: Diagnostic evaluation of developmental delay/mental retardation: An overview. American Journal of Medical Genetics Part C: Seminars in Medical Genetics, 117 (1): 3-14, 2003.

3- MCDONALD L.A. and RENNIE A.C.: Investigating developmental delay/impairment. Paediatrics and Child Health, 21 (10): 443-47, 2011.

4- FOO Y.L., CHOW J.C., LAI M.C., TSAI W.H., TUNG L.C., KUO M.C. and LIN S.J.: Genetic Evaluation of Children with Global Developmental Delay-Current Status of Network Systems in Taiwan. Pediatrics \& Neonatology, 56 (4): 213-9, 2015.

5- ALI A.S., SYED N.P., MURTHY G.S.N., NORI M., ABKARI A., POOJA B.K. and VENKATESWARLU J.: Magnetic resonance imaging (MRI) evaluation of developmental delay in pediatric patients. Journal of clinical and diagnostic research, JCDR, 9 (1): TC21, 2015.

6- JEONG J.W., SUNDARAM S., BEHEN M.E. and CHUGANI H.T.: Differentiation of Speech Delay and Global Developmental Delay in Children Using DTI Tractography-Based Connectome. American Journal of Neuroradiology, 2016.

7- PRANAY D.I. and CHITNIS D.A.: Evaluation of children with developmental delay using MRI. Paripex-Indian Journal of Research, Vol. 6 Issue 1, p. 9-11, 2018.
8- PALVE R., VERMA P., CHANDNANI S., KOTHARI S and KUMAR S.: MRI Evaluation of Brain in Children with Developmental Delay. International journal of contemporary medical research, Vol. 3, Issue 12, p. 3461-3, 2016.

9- JABEEN A., DILDAR N., NAYYAR B. and KHAN S. Role of MRI brain in diagnostic workup of children presenting with delaying milestones. Pakistan Armed Forces Medical Journal, 66 (3): 319-22, 2016.

10- DASAN T.A. and DEEPASHREE B.: The Role of Brain Magnetic Resonance Imaging in the Evaluation of Children with Global Developmental Delay In: International Journal of Anatomy, Radiology and Surgery; 2016.

11-BÉLANGER S.A. and CARON J.: Evaluation of the child with global developmental delay and intellectual disability. In Paediatrics \& Child Health, Vol. 23, No. 6, P. 403-10, 2018.

12- KONDE S.R., SASANE A, JAGTAP P.R. and BHOLE P.R.: MR imaging of the brain in children with developmental delay. Indian Journal of Applied Research, 7 (7): 46-8, 2018.

13- RAMYA K., SULAIMAN F.A.B. and ASHVIND D.: MRI Evaluation of Brain in Developmental Delay Children, 2018.

14- ARIF H.S., THEJEAL R.F. and FARHAN A.: Inborn errors of metabolism status in Iraq. IOSR J. Pharm. Biol. Sci., 11: 58-62, 2016.

15- ELMONEM M., Y.G. MARIAN, SELIM, LAILA, et al.: Lysosomal Storage Disorders in Egyptian Children. The Indian Journal of Pediatrics. 83. 10.1007/s12098-0152014-x, 2015. 


\section{دور الرنين المغناطيسى على الهيخ في حالات تآخر النهو عند الآطفال}

يوصف تآخر النمو الشامل كتآخر ملحوظ فى إثنين آق آكثر من مجالات النمو (الصركى، والإدراك، والكلام/اللغة، والثخصية/الإجتماعية).

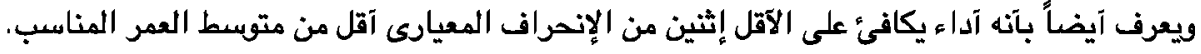

إن الهدف من هذه الدراسة هو تحديد مدى إنتشار نتائج التصوير بالرنين المغناطيسى الدماغى غير الطبيعية بين حالات تآخر النمو عند الآطفال الذين تتراوح آعمارهم بين بـ آثشهر إلى مدى إنى عاماً.

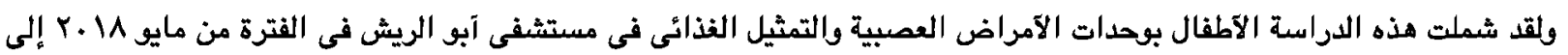

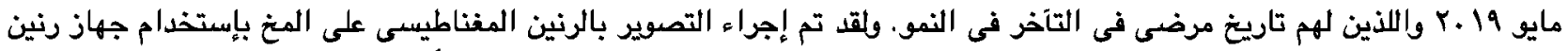

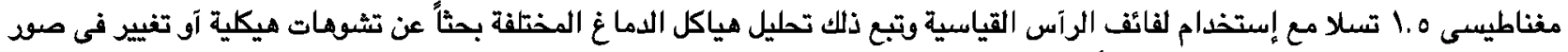

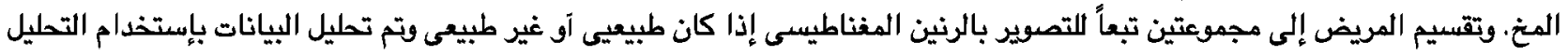
الإحصائى والذى آوضع النتائج التالية:

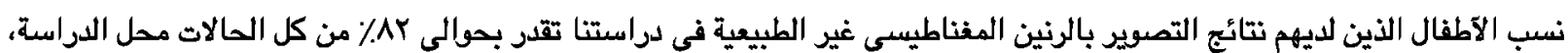

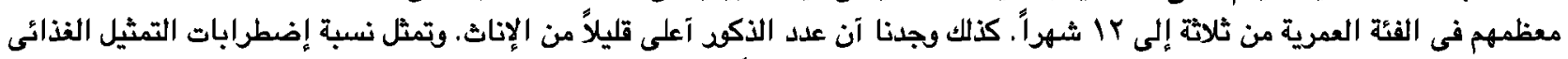

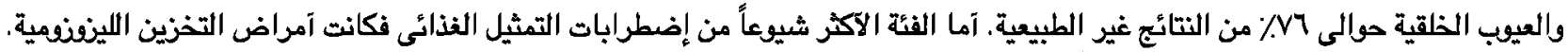

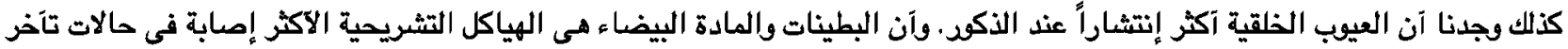

